\title{
New geomagnetic measurements in the Republic of Macedonia
}

\author{
Marjan Delipetrev ${ }^{1,{ }^{\star}}$, Nenad Novkovski ${ }^{2}$, Todor Delipetrov ${ }^{1}$ \\ ${ }^{1}$ University of Goce Delcev, Faculty of Natural and Technical Sciences, Stip, Republic of Macedonia \\ ${ }^{2}$ University of St. Cyril and Methodius, Faculty of Natural Science and Mathematics, Institute of Physics, Skopje, \\ Republic of Macedonia
}

\author{
Article history \\ Received July 13, 2011; accepted March 22, 2013. \\ Subject classification: \\ Geomagnetic survey, Geomagnetic field, Repeat station, Measurements.
}

\begin{abstract}
This study presents measurements of the geomagnetic field of the Republic of Macedonia, performed through a network of newly defined repeat stations. The measurements of these elements were in the intervals of $3.378^{\circ} \leq \Delta D \leq 3.983^{\circ}, 57.276^{\circ} \leq I \leq 59.005^{\circ}$, and $46235 n T \leq F \leq$ $46903 \mathrm{nT}$. The geomagnetic data were processed and the results of the observed elements of the geomagnetic field on the repeat stations are presented. Additional data processing was performed to calculate the reduced values of the intensive elements of the field at the level of $H_{500}$ a.s.l.. Based on these data, new maps of the geomagnetic field of the Republic of Macedonia are developed, together with the polynomial model of the elements of the geomagnetic field for the 2010.0 epoch.
\end{abstract}

\section{Introduction}

The territory of the Republic of Macedonia occupies the central part of the Balkans Peninsula, with an area of $25,713 \mathrm{~km}^{2}$. The terrain is mountainous due to highly active neotectonic processes. These processes have formed uplift blocks, with crests to 2,600 $\mathrm{m}$ a.s.l. and blocks of sinking depressions that mainly spread east to west [Arsovski 1997].

The geomagnetic investigations can be divided into three periods. The first period began in the $19^{\text {th }}$ century and finished in 1945. Scientists from mainly European countries were engaged in infrequent special expeditions to investigate the geomagnetic field in the Balkans, which included investigations in the territory of the present-day Republic of Macedonia. The second period was from 1945 to 1991, when Macedonia was a constitutional part of Yugoslavia, and the third period began after the declaration of independence in 1991.

The geomagnetic observations for the territory of the Republic of Macedonia up to 1990 were carried out by teams of scientists from the Geomagnetic Observatory Grocka (Republic of Serbia). To continue monitoring and to obtain new data for the geomagnetic field of Macedonia, Panovska and Delipetrov [2006] developed the appropriate maps and models for the given epochs. In 2002, the first measurements of the geomagnetic field for the locations of Plackovica, Ponikva and Galicica were initiated, with the help of the Royal Meteorological Institute Geomagnetic Observatory in Dourbes (Belgium). This report presents the results from the terrestrial measurements and data processing, and the newly developed maps and the polynomial model of the geomagnetic field of Macedonia.

\section{The repeat station network}

The geomagnetic field in a given area is measured for a network of repeat stations, often at five-year intervals. Based on these measurements, the raw geomagnetic data are collected and processed, which produces models and maps of the geomagnetic field elements.

A team from the Faculty of Natural Sciences, 'Goce Delcev' University (Stip, Republic of Macedonia) conducted investigations to define the repeat station network in the Republic of Macedonia. The repeat station networks of 16 countries were investigated, with the mean distance between stations of $230 \mathrm{~km}$, which varied from $53 \mathrm{~km}$ to $415 \mathrm{~km}$.

In the process of defining the repeat station network, geomagnetic measurements were performed for every point in four directions (north, south, east, west) at intervals of $1 \mathrm{~m}$ at a distance of $10 \mathrm{~m}$. The International Association of Geomagnetism and Aeronomy guidance states that the maximum gradient of the magnetic field for repeat stations should not exceed $50 \mathrm{nT}$ in a radius of $10 \mathrm{~m}$. The selected repeat stations in Macedonia have a gradient below $1 \mathrm{nT}$ [Rasson and Delipetrov 2006].

Based on these investigations and the characteristics of Macedonia, a network of 15 repeat stations was defined (Figure 1, Table 1). The minimum distance be- 


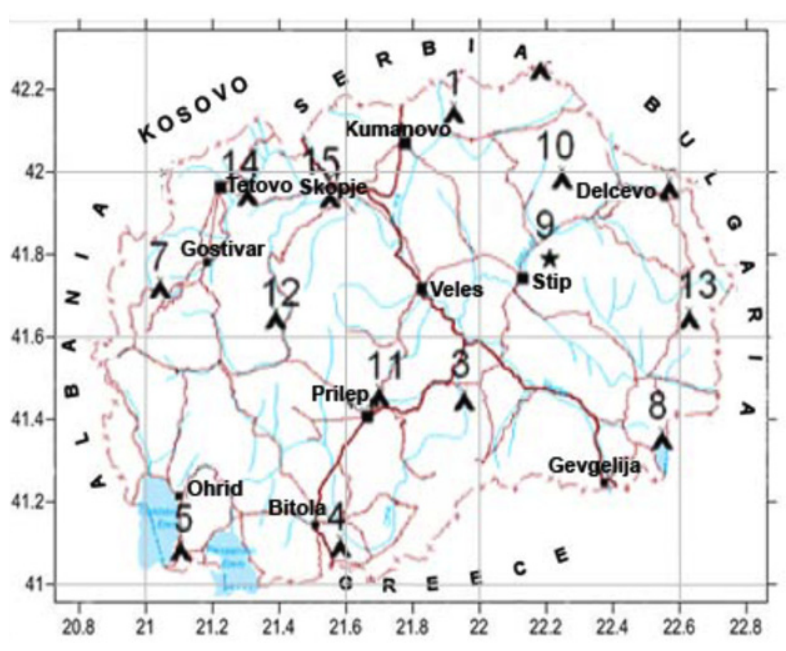

Figure 1. Map of the repeat stations in the Republic of Macedonia.

tween the repeat stations is $26.1 \mathrm{~km}$, with a maximum distance of $201.3 \mathrm{~km}$, and a mean distance of $98.6 \mathrm{~km}$. The lowest repeat station is Nikolic, at an altitude of 300 $\mathrm{m}$ a.s.l., while the highest is Galicica, at 1,684 $\mathrm{m}$ a.s.l.

\section{Normal geomagnetic field maps}

The first field measurements for the definition of the repeat station network were carried out in 20022003 with the instruments from the geomagnetic observatory in Dourbes (Belgium), with the help of Jean Rasson. The second series of geomagnetic field measurements was carried out in 2007-2009 for the newly established repeat station network (Table 1).

The repeat station measurements in 2007-2009 were performed with the instruments of the 'Goce Delcev' University. The instruments used were a LEMI 203
DIM sensor, a Geometrics G 856 proton magnetometer, and a Trimble global positioning system (GPS).

During the field observations, the declination D, inclination I, and total field vector $\mathrm{F}$ were measured. As there is no geomagnetic observatory available in the Republic of Macedonia, a time-series from the Panagjuriste Observatory (Bulgaria) was used. This observatory was selected due to its proximity, as it is 225 $\mathrm{km}$ away, with coordinates: latitude, $42.52^{\circ} \mathrm{N}$; longitude, $24.18^{\circ} \mathrm{E}$; altitude: $556 \mathrm{~m}$ a.s.l. The time-series data was used to reduce the results of the 2010.0 epoch, and to calculate the mean yearly changes in the geomagnetic field. The measurements for the 2010.0 epoch are given in Table 2 and illustrated in Figures 2-4.Using the data from Tables 1 and 2, a reduction of the intensive measurements was made to the level $h=500 \mathrm{~m}$ a.s.l. (Table 3).

For any intensive field element with a value $\mathrm{E}$ [e.g., De Santis et al. 2003] at a height $h$, the correction $\Delta \mathrm{E}$ for computing its value for $h=500 \mathrm{~m}$ is expressed as:

$$
|\Delta E|=\frac{3 E h}{R+h}=\frac{3 R h}{R}
$$

where $R=6,371.2 \mathrm{~km}$ is the Earth mean radius. Table 3 shows the corrections and reduced values for $\mathrm{F}_{500}, \mathrm{H}_{500}$ and $Z_{500}$. Using the software SURFER 9 and the data from Tables 2 and 3, the maps of the elements for the normal geomagnetic field were created (Figures 2-4).

The declination (D) in the observed area varies from $3.378^{\circ}$ for the repeat station Galicica, to $3.983^{\circ}$ for station Slivnica. The mean declination from the ob-

\begin{tabular}{|c|c|c|c|}
\hline Repeat station & $\begin{array}{l}\text { Geographic latitude } \\
\left(^{\circ}: \mathrm{min}: \mathrm{sec}\right)\end{array}$ & $\begin{array}{l}\text { Geographic longitude } \\
\left({ }^{\circ}: \mathrm{min}: \mathrm{sec}\right)\end{array}$ & $\begin{array}{l}\text { Altitude } \\
\text { (m) }\end{array}$ \\
\hline Bajlovce & $42: 13: 16$ & $21: 55: 17$ & 592 \\
\hline Crna skala & $41: 59: 41$ & $22: 47: 28$ & 833 \\
\hline Egri & $41: 23: 15$ & $21: 57: 06$ & 626 \\
\hline Galicica & $40: 57: 56$ & $21: 26: 54$ & 1684 \\
\hline Island Gradot & $40: 57: 23$ & $20: 48: 51$ & 317 \\
\hline Luke & $42: 20: 39$ & $22: 16: 29$ & 1180 \\
\hline Mavrovo & $41: 42: 58$ & $20: 43: 38$ & 1418 \\
\hline Nikolic & $41: 15: 54$ & $22: 44: 36$ & 300 \\
\hline Plackovica & $41: 47: 41$ & $22: 18: 13$ & 677 \\
\hline Ponikca & $42: 01: 35$ & $22: 21: 29$ & 1618 \\
\hline Prilep Lake & $41: 24: 11$ & $21: 36: 32$ & 870 \\
\hline Slivnica & $41: 37: 38$ & $21: 11: 36$ & 1252 \\
\hline St. Marija Precesna & $41: 36: 54$ & $22: 51: 46$ & 837 \\
\hline Tetovo & 41:59:09 & $21: 04: 46$ & 522 \\
\hline Vodno & $41: 58: 40$ & $21: 24: 57$ & 569 \\
\hline
\end{tabular}

Table 1. GPS coordinates of the repeat stations. 


\begin{tabular}{|c|c|c|c|c|c|c|c|}
\hline Station & $\begin{array}{l}\text { D } \\
\left({ }^{\circ}\right)\end{array}$ & $\begin{array}{c}\text { I } \\
\left({ }^{\circ}\right)\end{array}$ & $\begin{array}{c}\mathbf{F} \\
(\mathrm{nT})\end{array}$ & $\begin{array}{c}\mathbf{H} \\
(\mathrm{nT})\end{array}$ & $\begin{array}{c}\mathbf{X} \\
(\mathrm{nT})\end{array}$ & $\begin{array}{c}\mathbf{Y} \\
(\mathrm{nT})\end{array}$ & $\begin{array}{c}\boldsymbol{Z} \\
(\mathrm{nT})\end{array}$ \\
\hline Bajlovce & 3.507 & 58.850 & 46675 & 24144 & 24099 & 1477 & 39945 \\
\hline Crna Skala & 3.769 & 58.244 & 46903 & 24685 & 24632 & 1623 & 39881 \\
\hline Egri & 3.465 & 57.367 & 46330 & 24984 & 24938 & 1510 & 39016 \\
\hline Galicica & 3.378 & 57.276 & 46271 & 25014 & 24970 & 1474 & 38927 \\
\hline Island Gradot & 3.946 & 57.667 & 46327 & 24777 & 24719 & 1685 & 39144 \\
\hline Luke & 3.737 & 59.005 & 46235 & 23809 & 23759 & 1552 & 39633 \\
\hline Mavrovo & 3.466 & 58.122 & 46451 & 24531 & 24486 & 1483 & 39445 \\
\hline Nikolic & 3.499 & 57.823 & 46493 & 24759 & 24713 & 1511 & 39352 \\
\hline Plackovica & 3.698 & 58.217 & 46575 & 24531 & 24480 & 1582 & 39591 \\
\hline Ponikva & 3.721 & 58.603 & 46750 & 24355 & 24304 & 1581 & 39905 \\
\hline Prilep Lake & 3.509 & 57.854 & 46567 & 24777 & 24731 & 1517 & 39428 \\
\hline Slivnica & 3.983 & 58.166 & 46607 & 24583 & 24524 & 1708 & 39596 \\
\hline St. Marija Precesna & 3.533 & 58.039 & 46453 & 24590 & 24543 & 1515 & 39411 \\
\hline Tetovo & 3.617 & 58.346 & 46683 & 24499 & 24450 & 1546 & 39738 \\
\hline Vodno & 3.597 & 58.298 & 46671 & 24526 & 24477 & 1539 & 39707 \\
\hline
\end{tabular}

Table 2. Reduced measurements for the epoch 2010.5. D, declination; I, Inclination; T, Total intensity; H, Horizontal component; X, East component; Y, North component; Z, vertical component.

\begin{tabular}{lcccccc}
\hline Station & $\begin{array}{c}\Delta \mathrm{F}_{\mathbf{5 0 0}} \\
(\mathrm{nT})\end{array}$ & $\begin{array}{c}\Delta \mathbf{H}_{500} \\
(\mathrm{nT})\end{array}$ & $\begin{array}{c}\Delta \mathbf{Z}_{\mathbf{5 0}} \\
(\mathrm{nT})\end{array}$ & $\begin{array}{c}\mathbf{F}_{500} \\
(\mathrm{nT})\end{array}$ & $\begin{array}{c}\mathbf{H}_{500} \\
(\mathrm{nT})\end{array}$ & $\begin{array}{c}\mathbf{Z}_{\mathbf{5 0 0}} \\
(\mathrm{nT})\end{array}$ \\
\hline Bajlovce & 2.0219 & 1.0459 & 1.7201 & 46677.02 & 24145.05 & 39708.72 \\
Crna skala & 7.3540 & 3.8704 & 6.2530 & 46910.35 & 24688.87 & 39887.25 \\
Egri & 2.7487 & 1.4823 & 2.3148 & 46332.75 & 24985.48 & 39018.31 \\
Galicica & 25.7917 & 13.9429 & 21.6981 & 46296.79 & 25027.94 & 38948.70 \\
Island Gradot & -3.9921 & -2.1351 & -3.3731 & 46323.01 & 24774.86 & 39140.63 \\
Luke & 14.8024 & 7.6226 & 12.6888 & 46249.80 & 23816.62 & 39645.69 \\
Mavrovo & 20.0759 & 10.6022 & 17.0479 & 46471.08 & 24541.60 & 39462.05 \\
Nikolic & -4.3786 & -2.3317 & -3.7060 & 46488.62 & 24756.67 & 39348.29 \\
Plackovica & 3.8816 & 2.0444 & 3.2996 & 46578.88 & 24533.04 & 39594.30 \\
Ponikca & 24.6064 & 12.8190 & 21.0036 & 46774.61 & 24367.82 & 39926.01 \\
Prilep Lake & 8.1125 & 4.3164 & 6.8688 & 46575.11 & 24781.32 & 39434.87 \\
Slivnica & 16.5013 & 8.7037 & 14.0190 & 46623.50 & 24591.70 & 39610.02 \\
St. Marija Precesna & 7.3709 & 3.9018 & 6.2535 & 46460.27 & 24593.90 & 39417.25 \\
Tetovo & 0.4836 & 0.2538 & 0.4116 & 46683.48 & 24499.25 & 39738.41 \\
Vodno & 1.5163 & 0.7968 & 1.2901 & 46672.52 & 24536.80 & 39708.29 \\
\hline
\end{tabular}

Table 3. Corrections and reduced values for the intensive field elements at $h=500 \mathrm{~m}$ a.s.l.

served data is $\mathrm{D}_{\mathrm{sr}}=3.628^{\circ}$. The means of the geomagnetic fields are calculated using an arithmetic mean. Analysis of the declination field shows that for the observed territory, the most extreme value is in the central southern part, near the measuring station of Island Gradot. The field is quiet in the west and northwest parts of the country.

The observations show that the inclination varies from $57.276^{\circ}$ for Galicica to $59.005^{\circ}$ for Luke station.
The mean inclination (I) is $\mathrm{I}_{\mathrm{sr}}=58.125^{\circ}$. The inclination field compared to the declination is more homogenous and relatively quiet. There is a slight twisting of the isolines in the central-southern part. The measured points for the total field vector (F) vary from $46,235 \mathrm{nT}$ for Luke to $46,903 \mathrm{nT}$ for the repeat station Crna Skala. The mean total field vector is $\mathrm{F}_{\mathrm{sr}}=46,532 \mathrm{nT}$. The western part of the field, as the western-Macedonia part, has a quiet field. Again, there is a twisting of the iso- 


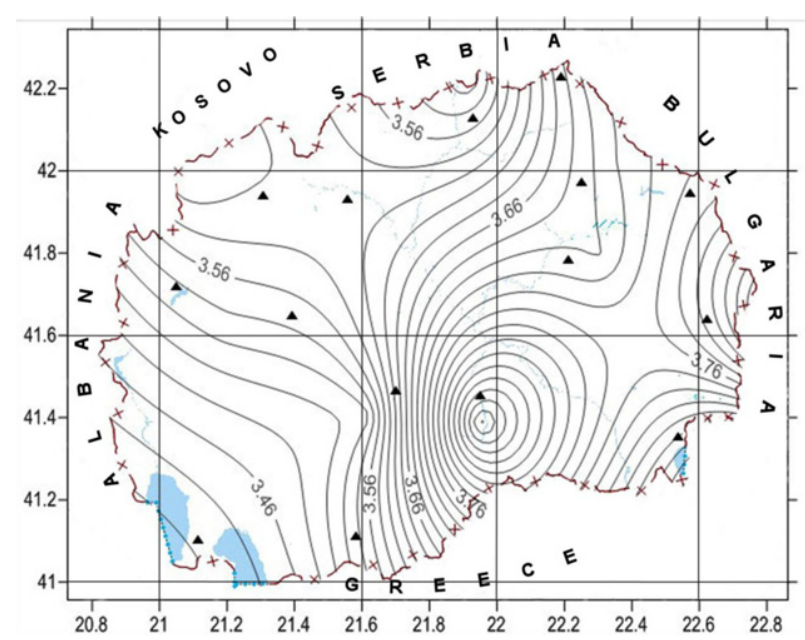

Figure 2. Map of the declination D for the 2010.0 epoch.

lines in the central-southern part.

The maps presented here (Figures 2-4) show that the largest deformations in the field occur in the central part and the eastern Macedonia zone.

The geomagnetic field on the Earth surface can be present as the vector sum of many different components:

$$
\vec{T}=\vec{T}_{0}+\vec{T}_{m}+\vec{T}_{a}+\vec{T}_{e}+\delta \vec{T}
$$

where, $\vec{T}_{0}$ is the field of the homogenous magnetized Earth, or the field of a dipole magnet, $\vec{T}_{m}$ is the field from the magnetic objects in the deeper parts of the Earth, known as the nondipole or field of continents, $\vec{T}_{a}$ is the field created by the magnetization of the upper parts of the Earth crust, known as the anomalous field, $\vec{T}_{e}$ is the field related to external phenomena with respect to the Earth surface, and $\delta \vec{T}$ is the field of variations.

With the measurement procedure performed and the processing of the collected data, components $\vec{T}_{e}$ and $\delta \vec{T}$ can be eliminated. The anomalous field $\vec{T}_{a}$ can be represented as a sum of two components:

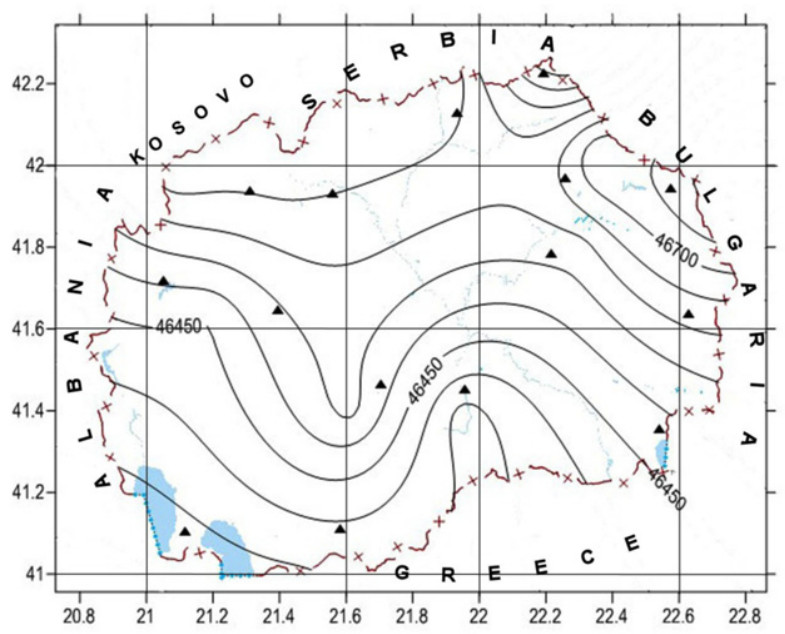

Figure 4. Map of total field vector F for the 2010.0 epoch.

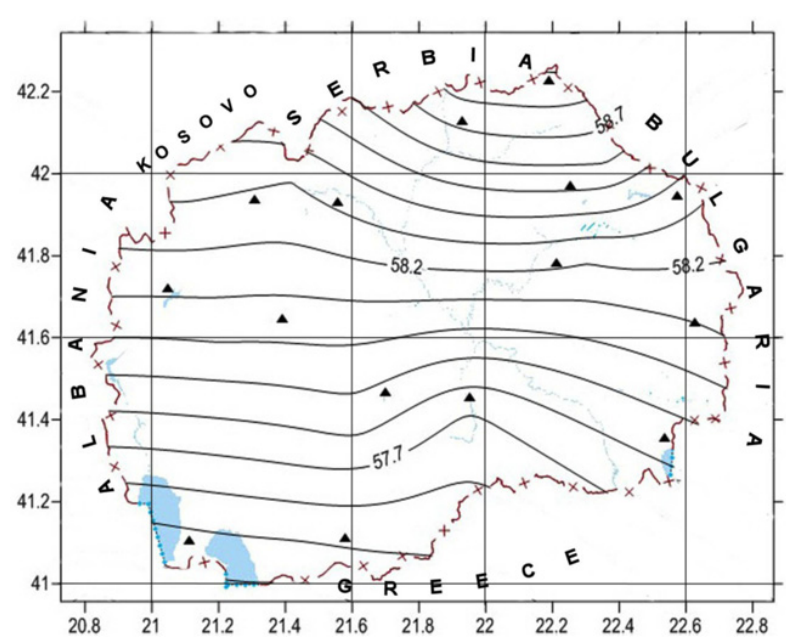

Figure 3. Map of the inclination I for the 2010.0 epoch.

$$
\vec{T}_{a}=\vec{T}_{a}^{r}+\vec{T}_{a}^{I}
$$

where, $\vec{T}_{a}^{r}$ is the regional anomalous field for the observed territory, which is caused by the influence of the magnetic layers and the deeper parts of the Earth crust, and which is manifest over larger areas, $\vec{T}_{a}^{r}$ is the local anomalous field for the observed territory. This field results from the magnetic media (rock, ore deposits) near the Earth surface, which influences a relatively small area. Separation of the local and anomalous fields depends on the size of the area investigated. The methodology and the observations of the geomagnetic field allow the elimination of the anomalous component of local character, $\vec{T}_{a}^{I}$.

The Italian Geomagnetic Reference Field models represent the geomagnetic field generated in the core, or the component $\left(T_{0}\right)$ and the nondipole field $\left(T_{m}\right)$, or the sum of these two.

The referent model for an investigated territory (state) is given by:

$$
\vec{T}_{N M}=\vec{T}_{0}+\vec{T}_{m}+\vec{T}_{a}^{r}
$$

The influence of the regional component presents specific geomagnetic features for the explored area that create differences from the global geomagnetic models of the Earth. For a more precise definition of the regional geomagnetic field, observations on a denser network of repeat stations should be made.

\section{Model of the normal geomagnetic field of the Re- public of Macedonia}

Today, two methods of modeling geomagnetic fields have been defined: one that uses spherical harmonic analysis, and the other, polynomial analysis. Studies show that for areas with $<15^{\circ}$ spatial angle, polynomial analysis is an effective method [De Santis et al. 1999]. Given the size of the territory of the Repub- 


\begin{tabular}{lccccc}
\hline Element & \multicolumn{5}{c}{ Coefficient } \\
\cline { 2 - 6 } & $\mathbf{a}_{\mathbf{0}}$ & $\mathbf{a}_{\mathbf{1}}$ & $\mathbf{a}_{\mathbf{2}}$ & $\mathbf{a}_{\mathbf{3}}$ & $\mathbf{a}_{\mathbf{4}}$ \\
\hline $\mathbf{D}\left(^{\circ}\right)$ & 3.6278 & 0.1176 & -0.0386 & 0.0778 & 0.0154 \\
$\mathbf{I}\left(^{\circ}\right)$ & 58.0876 & -0.0367 & -0.1578 & 0.1196 & -0.3455 \\
$\mathbf{T}(\mathrm{nT})$ & 46550 & -24.4499 & -172.2784 & -20.5894 & 197.7838 \\
$\mathbf{H}(\mathrm{nT})$ & 24607 & 11.0723 & 17.1495 & -95.3759 & 38.9003 \\
$\mathbf{X}(\mathrm{nT})$ & 24558 & 7.9397 & 18.2187 & -97.3217 & 37.0952 \\
$\mathbf{Y}(\mathrm{nT})$ & 15560 & 46.6355 & -15.9659 & 23.6280 & -449.6354 \\
$\mathbf{Z}(\mathrm{nT})$ & 39514 & -36.4622 & -217.0881 & 33.5642 & -13.3079 \\
\hline
\end{tabular}

Table 4. Model for the 2010.0 epoch.

lic of Macedonia, the polynomial model is appropriate.

To calculate the coefficients of the polynomial model, the method of least squares is used. The geomagnetic field for a given territory can be expressed as:

$$
\begin{gathered}
E(\Delta \varphi, \Delta \lambda)=a_{1}+a_{2} \cdot \Delta \varphi+a_{3} \cdot \Delta \lambda+ \\
+a_{4} \cdot \Delta \varphi^{2}+a_{5} \cdot \Delta \lambda^{2}+a_{6} \Delta \varphi \cdot \Delta \lambda
\end{gathered}
$$

where, $E(\Delta \varphi, \Delta \lambda)$ is a normal field of the point with coordinates $\varphi_{1}$ and $\lambda_{1}, \varphi_{1}$ and $\lambda_{1}$ are the geographic latitude and longitude of the point, respectively, $\varphi_{0}$ and $\lambda_{0}$ are the geographic latitude and longitude of the point, respectively, in respect of which the measurements are reduced. For the Republic of Macedonia, the central point is for $\varphi_{0}=41.50^{\circ}$ and $\lambda_{0}=22^{\circ}$. Then, $\Delta \varphi=\varphi_{1}-$ $-\varphi_{0}$ is the difference in the geographic latitudes, in minutes, $\Delta \lambda=\lambda_{1}-\lambda_{0}$ is the difference in the geographic longitudes, in minutes, and $a_{i}$ is the coefficient for the corresponding differences in $\mathrm{nT} / \mathrm{min}$; i.e., $\mathrm{min} / \mathrm{min}$. Usually, the differences in the latitude and longitude are calculated in terms of the coordinates of the geomagnetic observatory located in that territory.

The normal field of the territory of Macedonia is calculated according to the measurements of absolute values for the total intensity (F), declination (D) and inclination (I) for the period from 2007-2009 for the 15 network stations. The values for the other components of the geomagnetic field are derived from these (Table 1). Calculate coefficients or polynomial model from the absolute measurements for 2010.0 epoch is given in (Table 4).

\section{Conclusions}

This report presents the measurements of the geomagnetic field of the Republic of Macedonia. The geomagnetic field observations were carried out for the newly developed repeat station network in 2007-2009. The data gathered was processed and the maps of the geomagnetic field elements are produced here. With the reduction in $\mathrm{H}_{500}$ a.s.l., the influence of the relief was minimized in relation to the regional magnetic com- ponent presented. The data are used to create the polynomial model of the elements of the geomagnetic field for the 2010.0 epoch. The model is a second-degree polynomial in longitude and latitude and consists of observations of six coefficients for each magnetic element.

The measurements given in this report are a continuation of the observations on the geomagnetic field in the Republic of Macedonia that was started after 2000. The geomagnetic model can be used for further studies and analysis of the geomagnetic field of this area.

Acknowledgements. The authors would like to thank Dr Jean Rasson, Royal Meteorological Institute Geomagnetic Observatory, Dourbes, Belgium, for help with the recording in 20022003, the University of Goce Delcev, for support from the Tempus Project Geomagnetic measurements and quality standards, and the Panagjuriste Observatory, Bulgaria, for the geomagnetic observatory time-series.

\section{References}

Arsovski, M. (1997). Tectonics of Macedonia, Faculty of Geology and Mining, Stip (Republic of Macedonia), 18-25.

De Santis, A., J.M. Torta and F.J. Lowes (1999). Spherical cap harmonics revisited and their relationship to ordinary spherical harmonics, Phys. Chem. Earth, Part A: Solid Earth Geod., 24 (11/12), 935-941.

De Santis, A., L. Gaya-Piqué, G. Dominici, A. Meloni, J.M. Torta and R. Tozzi (2003). Italian Geomagnetic Reference Field (IGRF): update for 2000 and secular variation model up to 2005 by autoregressive forecasting, Annals of Geophysics, 46 (3), 491-500.

Delipetrov, T., and B. Paneva (2006). Geomagnetic field of the Republic of Macedonia, In: J.L. Rasson and T. Delipetrov (eds), Geomagnetics for aeronautical safety: a case study in and around the Balkans, Proceedings of the NATO Advanced Research Workshop (Ohrid, Republic of Macedonia, 16-20 May 2005), Springer, 15-42.

Panovska, S., and T. Delipetrov (2006). Analysis of geomagnetic field data from measurements during 2003 in Macedonia, In: J.L. Rasson and T. Delipetrov 
(eds), Geomagnetics for aeronautical safety: a case study in and around the Balkans, Proceedings of the NATO Advanced Research Workshop (Ohrid, Republic of Macedonia, 16-20 May 2005), Springer, 325-346.

Rasson, J.L., and M. Delipetrov (2006). Repeat surveys of Macedonia, In: J.L. Rasson and T. Delipetrov (eds), Geomagnetics for aeronautical safety: a case study in and around the Balkans, Proceedings of the NATO Advanced Research Workshop (Ohrid, Republic of Macedonia, 16-20 May 2005), Springer, 97-114.

${ }^{\star}$ Corresponding author: Marjan Delipetrev, University of Goce Delcev, Faculty of Natural and Technical Sciences, Stip, Republic of Macedonia; email:marjan.delipetrev@ugd.edu.mk. 